\title{
Erratum to: Effects-based spatial assessment of contaminated estuarine sediments from Bear Creek, Baltimore Harbor, MD, USA
}

\author{
Sharon E. Hartzell ${ }^{1}$ - Michael A. Unger ${ }^{2} \cdot$ Beth L. McGee $^{3}$ - Lance T. Yonkos ${ }^{1}$
}

Published online: 4 October 2017

(C) Springer-Verlag GmbH Germany 2017

Erratum to: Environ Sci Pollut Res (2017) 24:22158-22172

https://doi.org/10.1007/s11356-017-9667-0

The original publication of this paper contains an error.

The correct image of figure 5 is shown in this paper.

The online version of the original article can be found at https://oi.org/ $10.1007 / \mathrm{s} 11356-017-9667-0$

\section{Lance T. Yonkos}

lyonkos@umd.edu

1 Environmental Science and Technology Department, University of Maryland, 1451 Animal Science Bldg, College

Park, MD 20742-2315, USA

2 Virginia Institute of Marine Science, College of William \& Mary, 1208 Greate Road, Gloucester Point, VA 23062, USA

3 Chesapeake Bay Foundation, Philip Merrill Environmental Center, 6 Herndon Avenue, Annapolis, MD 21403, USA 


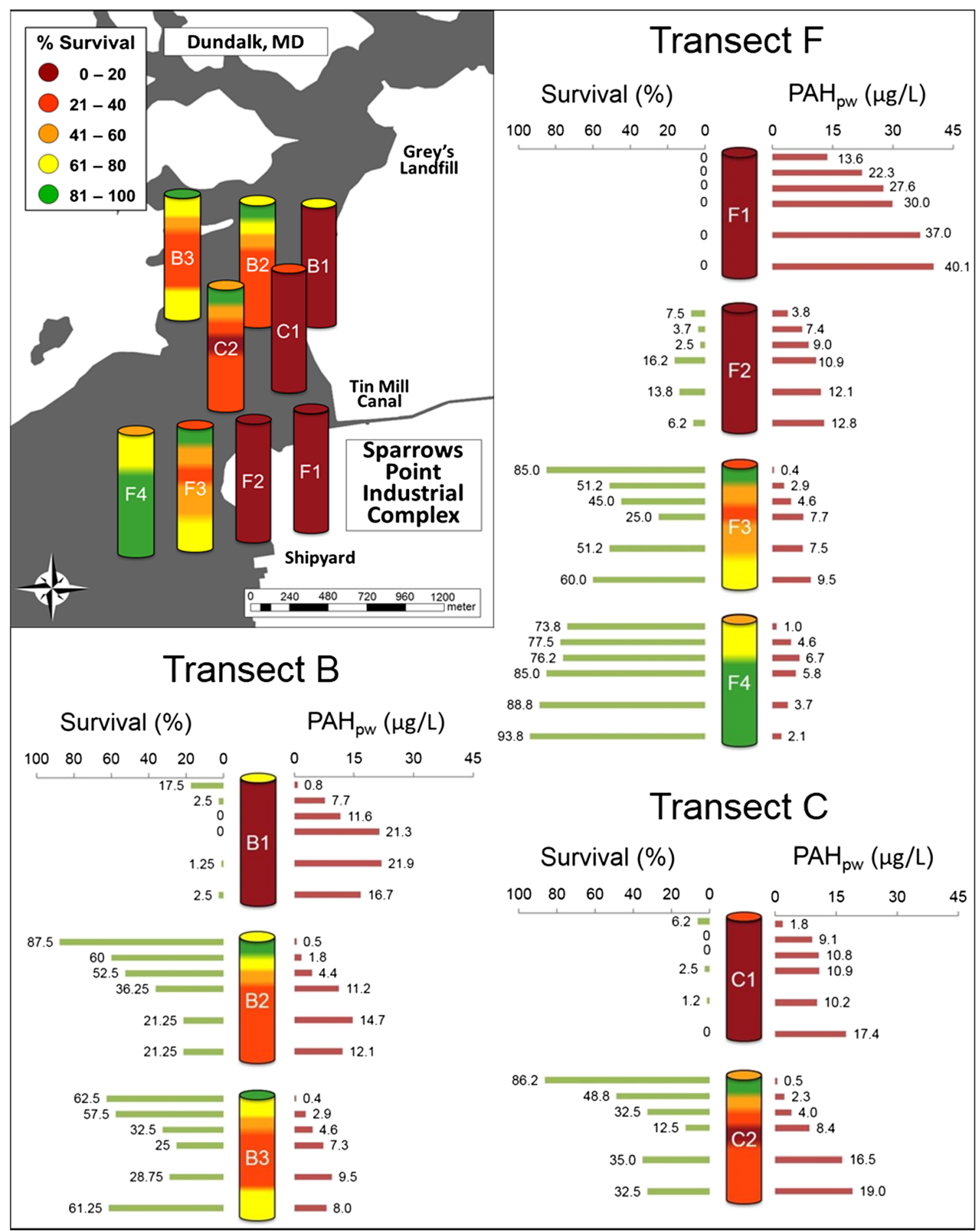

Fig. 5 Percent survival (color-coded) of Leptocheirus plumulosus following 10-day exposures to sediments from the surface (top disk) and at depth intervals $(0-10,10-20,20-30,30-40,40-60,60-80 \mathrm{~cm})$ within sediment cores, and depth distribution of survival (left) and porewater polycyclic aromatic hydrocarbon (PAHpw; right) within individual core segments from B, C, and F transects (PAHpw of surface sediments are not shown) 